\title{
Mosquitoes collected on Weno Island, Romanum Island and Piis- Paneu Island, Chuuk State, the Federated States of Micronesia (Diptera: Culicidae)
}

\author{
Shinichi NodA ${ }^{*, 1)}$, Sota Yamamoto ${ }^{1)}$ and Takako Toma ${ }^{2)}$ \\ * Corresponding author: Kagoshima University Research Center for the Pacific Islands, 1-21-24 Korimoto, \\ Kagoshima 890-8580, Japan (E-mail: snoda@cpi.kagoshima-u.ac.jp) \\ ${ }^{1)}$ Kagoshima University Research Center for the Pacific Islands, 1-21-24 Korimoto, Kagoshima 890-8580, Japan \\ 2) Laboratory of Medical Zoology, School of Health Sciences, Faculty of Medicine, University of the Ryukyus, 207 \\ Uehara, Nishihara, Okinawa 903-0215, Japan
}

(Received: 17 September 2013; Accepted: 25 December 2013)

\begin{abstract}
Mosquito larval surveys were carried out on Weno Island, Romanum Island and Piis-Paneu Island, in Chuuk State, the Federated States of Micronesia in August 2011. Larvae were collected from 133 natural and artificial habitats. A total of 1,761 larvae belonging to nine species including one unidentified species were collected. On Weno Island, eight species, Aedes hensilli, Ae. albopictus, Ae. lamelliferus, Aedes sp., Culex quinquefasciatus, Cx. carolinensis, $C x$. annulirostris and Lutzia vorax, were collected. Four species were collected on Romanum Island; Ae. scutoscriptus, Ae. hensilli, Cx. quinquefasciatus and Cx. carolinensis and six species were collected on PiisPaneu Island; Ae. scutoscriptus, Ae. hensilli, Aedes sp., Cx. quinquefasciatus, Cx. carolinensis and Cx. annulirostris. We determined that 1) Ae. albopictus and Lt. vorax were newly reported in Chuuk State, 2) Ae. hesilli was the predominant species on both Weno Island and Piis-Paneu Island and distributed in Romanum Island and 3) that Ae. albopictus existed on Weno Island. Environmental management program seeks to alter the environment to prevent to minimize vector propagation and human contact with the vector-pathogen. Recommended changes to the environment include destroying, altering, removing or recycling nonessential containers that provide larval habitats for these species of mosquitoes.
\end{abstract}

Key words: Aedes hensilli, Aedes albopictus, mosquito fauna, Chuuk State, Federated States of Micronesia

\section{INTRODUCTION}

Major vectors for dengue fever and dengue hemorrhagic fever are Aedes aegypti and Ae. albopictus. In the Pacific islands, Ae. polynesiensis, a member of the Ae. scutellaris complex, has also been designated as a vector, along with several other miner species (WHO, 2003). The dengue fever outbreak in Yap State, the Federated States of Micronesia (FSM), was reported between June and July 1995 (Savage et al., 1998). Entomological investigations designated the native mosquito species, Ae. hensilli, as a vector of dengue virus (Savage et al., 1998; Noda et al., 2005). Another dengue fever outbreak occurred in Yap from May 2004 to January 2005 after Typhoon Sudal where six cases were exported to Japan via a visiting group of school children; however, there was no known secondary spread from this case (Martin, 2005; Nukui et al., 2006). Dengue cases have reliably occurred in Yap every year since 2007 (WHO Home page). In 2001, dengue infections were identified on three of the six islands of Hawaii. During the investigation, 1,644 persons with locally acquired dengue-like illness were evaluated, and 122 (7\%) laboratory-positive dengue infections were identified. Aedes albopictus was present in all communities surveyed on these three islands, but unexpectedly, no Ae. aegypyi were found (Effler et al., 2005).

The FSM include four states: Yap, Chuuk, Pohnpei, and Kosrae. These areas form the Caroline Island chain together with Palau. There is a possibility of dengue fever outbreak in other states of the FSM, however, there is currently little information on the mosquito species, that may be the vector to this diseases. This report describes the geographical distribution and breeding sites of mosquito fauna on Weno Island, Romanum Island and Piis-Paneu Island, in Chuuk State, the FSM.

\section{Materials and Methods}

Three geographically different islands were chosen as an investigation place. Surveys of larval mosquitoes on Weno Island, Romanum Island and Piis-Paneu Island, in Chuuk State, the FSM, were carried out in August 2011 (Fig. 1). Larvae of mosquitoes were also collected supplementary on Tonoas Island which is located just south of Weno Island. Chuuk State is composed of 192 outer islands, which include 15 main islets and more than 80 smaller islets that make up Chuuk Lagoon. Annual rainfall averages $3,632 \mathrm{~mm}$ in Chuuk Lagoon, and humidity is high year round (Galbraith et al., 2000). 


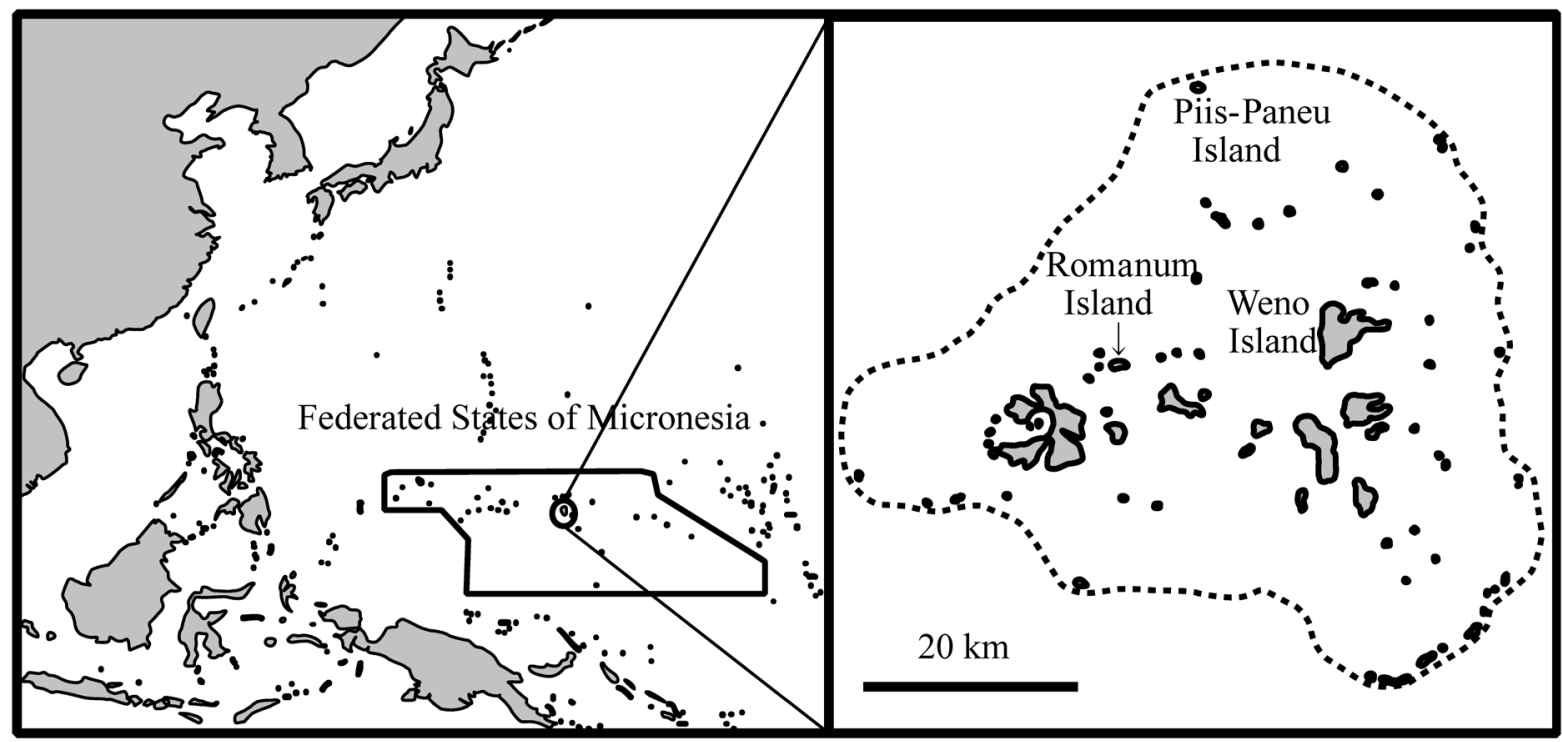

Fig. 1. A map of Chuuk Atoll. Mosquito larval surveys were carried out on Weno Island, Romanum Island and Piis-Paneu Island, Chuuk State, the Federated States of Micronesia.

The average annual temperature is a fairly constant $\left(27^{\circ} \mathrm{C}\right)$. About 40 of the state's islands are inhabited. Chuuk is the one of Micronesia's most populous islands, with a population of 48,651 people (estimated in 2010), of which approximately one-third live on Weno Island.

Weno Island is the main island, and the district center of the Chuuk State. It contains the majority of the state government offices as well as an airport on the northwest coast. Many people frequently visit Weno Island from other islands for work, trading, shopping or other purposes. At just over $18 \mathrm{~km}^{2}$, it is the second largest island in the lagoon. Tropical forests make up much of the interior, with the highest point being Mt. Tonoken $(370 \mathrm{~m})$ located in the island's center. Villages circle the outer edge of Weno Island, and the district center, government offices and airport are on the northwest side of the island. Romanum Island is also located in the lagoon, and is less than $1 \mathrm{~km}^{2}$. This island is hilly and the highest point is only $54 \mathrm{~m}$ above sea level. Houses are scattered throughout the island, and the population is approximately 300 people. PiisPaneu Island is located on the atoll ring reef, it is also less than $1 \mathrm{~km}^{2}$. The elevation is consistently near sea level, houses are scattered throughout the island, and the population is approximately 250 people.

Larval collections were carried out around houses by visiting house to house. If there are containers with water or natural puddles between houses, they were examined. Larval collections were made with a pipette and dipper. When a habitat was small, all of the larvae were collected. When a habitat was large, fewer than 30 larvae were collected. Young larvae that were unable to be identified to species were excluded in the results of this paper. Collected larvae were preserved in $70 \%$ ethanol, and some larvae were reared to the adult stage. Larval collections were made at 133 habitats: Weno
Island ( 86 habitats), Romanum Island (21 habitats), and Piis-Paneu Island (26 habitats). The sampled habitats were composed of a variety of materials, namely; coconut shells, rock pits, tree holes, banana stumps, wells, puddles, taro fields as well as artificial containers such as concrete puddles, plastic water barrels, discarded drink cans, glass containers, plastic containers, rubber containers, metal containers, buckets, plastic bags, pans, tires, freezers, washing machines and a track loading platform.

Identification of larvae and adults was completed by using morphological keys and descriptions from Bohart (1957) and Bohart and Ingram (1946). Classification of the species belonging to the genera Lutzia follows the description from Tanaka (2003).

\section{RESULTS}

A total of 1,761 larvae belonging to nine species, including one unidentified species, were collected at a total of 133 habitats in this survey. A novel finding in this survey was that Ae. albopictus and Lt. vorax were both reported in Chuuk State. In Weno Island a total of 1,180 larvae belonging to eight species, including one unidentified species were collected at a total of 86 sites that were defined as either natural or artificial. As the area and population of Weno Island is large, there were many kinds of source of mosquito larvae. They were identified as Ae. (Stegomyia) hensilli, Ae. (Stg.) albopictus, Aedes (Stg.) sp., Ae. (Skusea) lamelliferus, $C x$. (Cux.) quinquefasciatus, Cx. (Cux.) carolinensis, Cx. (Cux.) annulirostris and Lutzia (Metalutzia) vorax (Table 1). Culex carolinensis was the predominant species collected (656 larvae, 41 habitats) followed by Ae. hensilli (318 larvae, 44 habitats). Aedes albopictus was collected from discarded containers along the main road in northwest side of Weno Island. As larvae of two 
Table 1. The number of mosquitoes and their habitat types collected on Weno Island, Chuuk State, Federated States of Micronesia.

\begin{tabular}{|c|c|c|c|}
\hline Species & No. of individuals & Number of habitats* & Habitat types (No. of habitats) \\
\hline Aedes (Stegomyia) hensilli & 318 & 44 & $\begin{array}{l}\text { Coconut shells (14), Drink cans (9), Glass containers (4), } \\
\text { Plastic bag (1), Plastic containers (9), Metal container (1), } \\
\text { Bucket (1), Tires (3), Freezer (1), Plastic water barrel (1) }\end{array}$ \\
\hline Aedes (Stegomyia) albopictus & 41 & 10 & $\begin{array}{l}\text { Coconut shells (2), Drink cans (5), Plastic container (1), } \\
\text { Rubber container (1), Tire (1) }\end{array}$ \\
\hline Aedes (Stegomyia) sp. & 1 & 1 & Coconut shell (1) \\
\hline Aedes (Skusea) lamelliferus & 11 & 1 & Coconut shell (1) \\
\hline Culex (Culex) quinquefasciatus & 72 & 6 & Coconut shells (3), Pan (1), Tire (1), Washing machine (1) \\
\hline Culex (Culex) carolinensis & 656 & 41 & $\begin{array}{l}\text { Coconut shells (18), Drink cans (7), Plastic containers (6), } \\
\text { Rubber container (1), Bucket (1), Tires (8) }\end{array}$ \\
\hline Culex (Culex) annulirostris & 80 & 6 & $\begin{array}{l}\text { Drink can (1), Glass container (1), Bucket (1), Concrete } \\
\text { puddle (1), Track loading platform (1), Taro field (1) }\end{array}$ \\
\hline Lutzia (Metalutzia) vorax & 1 & 1 & Drink can $(1)$ \\
\hline
\end{tabular}

* Total number of habitat is 86 .

Table 2. The mumber of mosquitoes and their habitat types collected on Romanum Island, Chuuk State, Federated States of Micronesia.

\begin{tabular}{lccl}
\hline \hline Species & No. of individuals & Number of habitats* & \multicolumn{1}{c}{ Habitat types (No. of habitats) } \\
\hline $\begin{array}{l}\text { Aedes (Stegomyia) hensilli } \\
\text { Aedes (Stegomyia) scutoscriptus }\end{array}$ & 23 & 4 & Coconut shell (1), Drink can (1), Rock pits (2) \\
& 99 & 11 & $\begin{array}{l}\text { Coconut shells (2), Banana stumps (2), Drink can (1), Glass } \\
\text { container (1), Rock pits (2), Plastic containers (3) }\end{array}$ \\
Culex (Culex) quinquefasciatus & 16 & 3 & $\begin{array}{l}\text { Coconut shell (1), Glass container (1), Well (1) } \\
\text { Culex (Culex) carolinensis }\end{array}$ \\
& 66 & 4 & $\begin{array}{l}\text { Coconut shell (1), Glass container (1), Pan (1), Plastic water } \\
\text { barrel (1) }\end{array}$ \\
\hline
\end{tabular}

* Total number of habitat is 21 .

Table 3. The number of mosquitoes and their habitat types collected on Piis-Paneu Island, Chuuk State, Federated States of Micronesia.

\begin{tabular}{lccl}
\hline \hline \multicolumn{1}{c}{ Species } & No. of individuals & Number of habitats* & \multicolumn{1}{c}{ Habitat types (No. of habitat) } \\
\hline Aedes (Stegomyia) hensilli & 82 & 8 & Coconut shells (4), Drink cans (3), Pan (1) \\
Aedes (Stegomyia) scutoscriptus & 65 & 10 & Coconut shells (5), Drink can (1), Banana stump (1), Tree \\
& & & hole (1), Plastic containers (2) \\
Aedes (Stegomyia) sp. & 17 & 2 & Well (1), Taro field (1) \\
Culex (Culex) quinquefasciatus & 59 & 3 & Tree hole (1), Concrete puddle (1), Puddle (1) \\
Culex (Culex) carolinensis & 105 & 7 & Coconut shells (4), Drink can (1), Taro fields (2) \\
Culex (Culex) annulirostris & 49 & 3 & Puddle (1), Taro fields (2) \\
\hline
\end{tabular}

* Total number of habitat is 26 .

species lived in the same habitat together, the total of the habitat of each species became larger than the total of a habitat.

In Romanum Island, a total of 204 larvae belonging to four species were collected at 21 sites defined as either natural or artificial habitats. They were identified as $A e$. hensilli, Ae. (Stg.) scutoscriptus, Cx. quinquefasciatus and Cx. carolinensis (Table 2). Aedes scutoscriptus was the predominat species collected (99 larvae, 11 habitats).

In Piis-Paneu Island, a total of 377 larvae belonging to six species, including one unidentified species, were collected at 26 sites. They were identified as Ae. hensilli, Ae. scutoscriptus, Aedes (Stg.) sp., Cx. quinquefasciatus, $C x$. carolinensis and Cx. annulirostris (Table 3). Culex carolinensis was the predominant species collected (105 larvae, 7 habitats) followed by Ae. hensilli (82 larvae, 8 habitats).

The distribution of mosquitoes on three islands of Chuuk State is shown in Table 4. Aedes hesilli, a main vector of dengue fever in Yap State (Savage et al., 1998; Noda et al., 2005), was collected on three islands.

\section{Discussion}

A total of five Aedes species were collected on Weno Island and Piis-Paneu Island. Aedes hesilli was the predominant species on both Islands but is also distributed in Romanum Island. Aedes hesilli is a main vector of dengue fever in Yap State (Savage et al., 1998; Noda et al., 2005) and appears to be an important vector of dengue fever in Chuuk State. Bohart (1957) reported that Ae. hesilli was distributed in Palau, Yap State and Chuuk State. Surveys of larval mosquitoes were carried out on Pohnpei State and Kosrae State, but Ae. hesilli was not collected in both areas (Noda et al., 2013a and 2013b). The distribution of Ae. hesilli was still limited to the west area in the FMS.

Aedes albopictus, which is considered to be a major vector of dengue fever, was collected on Weno Island. 
Table 4. Distribution of mosquito species on three islands of Chuuk State, the Federated States of Micronesia.

\begin{tabular}{lcc}
\hline \multicolumn{1}{c}{ Species } & Weno Island & Romanum Island \\
\hline Aedes (Stegomyia) hensilli & $\bigcirc$ & $\bigcirc$ \\
Aedes (Stegomyia) albopictus & $\bigcirc$ & $\bigcirc$ \\
Aedes (Stegomyia) scutoscriptus & & \\
Aedes (Stegomyia) sp. & $\bigcirc$ & \\
Aedes (Skusea) lamelliferus & $\bigcirc$ & $\bigcirc$ \\
Culex (Culex) quinquefasciatus & $\bigcirc$ & $\bigcirc$ \\
Culex (Culex) carolinensis & $\bigcirc$ & $\bigcirc$ \\
Culex (Culex) annulirostris & $\bigcirc$ & $\bigcirc$ \\
Lutzia (Metalutzia) vorax & 0 & $\bigcirc$ \\
\hline
\end{tabular}
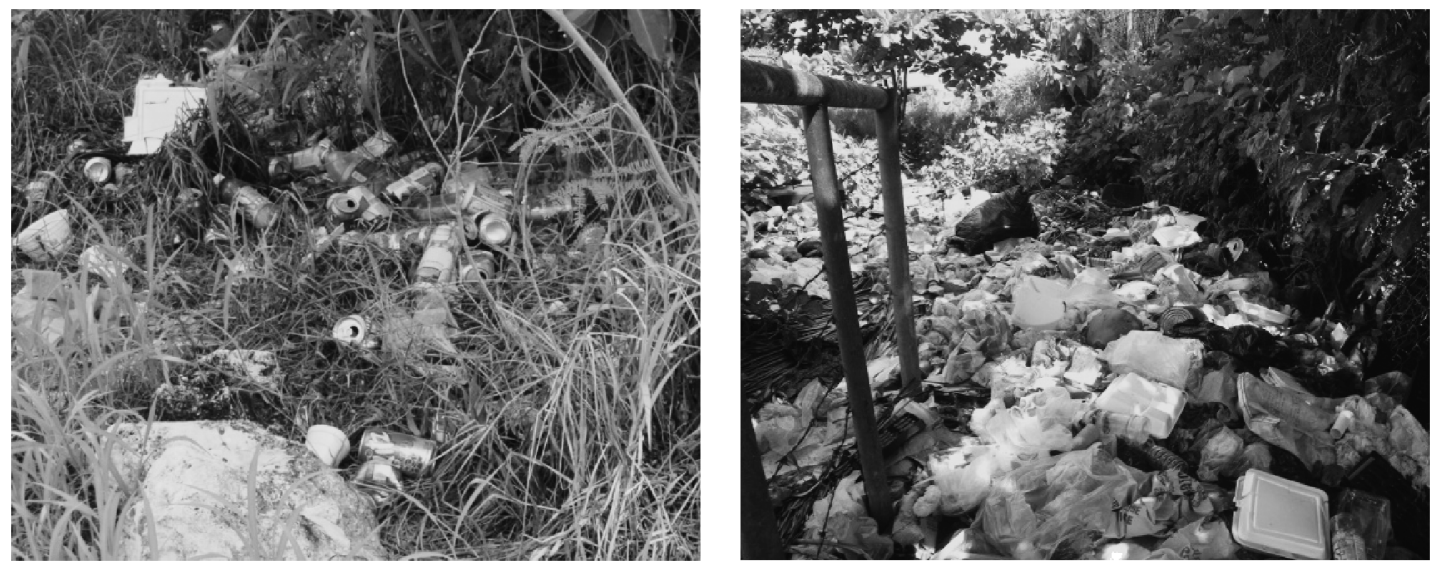

Fig. 2. Tins and a lump of garbage dust along the main street of Weno Island.

The dengue virus was brought into Kosrae State in 2012. Among the 230 patients with suspected dengue infections in the state, 85 were confirmed positive between 26 September and 11 November (2012) (Ministry of Foreign Affairs of Japan, 2011, 2012). Our entomological survey suggests that Ae. albopictus may have been a vector in transmitting the dengue virus to Kosrae State, the FSM (Noda et al., 2013b). Aedes albopictus was not collected in the FMS by Bohart (1957). It was not collected on Yap State (Noda et al., 2005). However, the distribution of Ae. albopictus in the FMS was confirmed on Chuuk State by present survey, and it was also confirmed on Pohnpei Island and Mokil Atoll (Pohnpei State) and Kosrae State (Noda et al., 2013a and 2013b). Aedes albopictus distributed mainly in the east area of the FSM. Aedes (Stegomyia) sp. from Weno Island and Piis-Paneu Island were damaged larval specimens. The pupa and adult are unknown. The specimens are closely related to Ae. albopictus in characters of comb and pecten teeth. This species will be identified when the specimens associated a series of pupal and adult stages are obtained.

From our survey, we suggest that Weno Island, Romanum Island and Piis-Paneu Island all seem to be highly dengue-sensitive areas due to the mosquito species distributed on them. Mosquito surveys were carried out on only three islands of Chuuk lagoon but the mosquito species distribution and density appears to be the same on other islands of Chuuk lagoon. On Tonoas
Island, which is located just south of Weno Island, distributions of Ae. albopictus and Ae. scutoscriptus were confirmed at the same period, although the results of the survey are not reported in the present paper.

On Weno Island, larvae of Ae. aegypti were discovered in metal drums (Bohart and Ingram, 1946). However, along the northern coast, which was inhabited mostly by native peoples, no larvae of this species were found. Aedes aegypti were not discovered at other sampling sites, although these sites provided suitable breeding habitats for this species (Bohart and Ingram, 1946). Aedes aegypti was not collected on three of the islands in this survey, the importance of Ae. aegypti may be low as a vector for dengue fever. As the distribution of $A e$. aegypti was confirmed on Pohnpei Island and Pingelap Atoll (Pohnpei State), it is necessary to pay attention to the distribution of Ae. aegypti (Noda et al., 2013a).

As Weno Island is one of the most densely populated islands in the FSM, it has pollution problems, including sewage that runs into lagoons and garbage-littered streets (Galbraith et al., 2000). Figure 2 shows tins and disintegrated garbage piles along the main street of Weno Island. This situation is unique to Weno and is not repeated on any island in the other three states. The garbage on Weno Island's main street provides ideal sites for Aedes, and larvae from this genus were frequently collected from discarded containers along the main road. This scenario presents the habitat and appropriate species for potential outbreak of dengue fever on Weno 
Island. The large flow of people from Weno Island to other islands, as well as the distribution and density of Aedes mosquitoes, implies that this outbreak could easily spread to other islands or countries. For example, in 2012, one male construction worker from the Marshall Islands was confirmed to have contracted dengue fever on Weno Island (personal communication).

In 2007 Zika virus, a relatively mild disease similar to dengue fever but is instead characterized by a tropical rash and joint pain was reported on Yap Island, the FSM. This was the first report of Zika virus outside of either Africa or Asia (Duffy et al., 2009; Hayes, 2009). Aedes hensilli was the predominant mosquito species identified as a vector for this virus. Another example involves Chikungunya virus, which is also transmitted to humans by Aedes mosquitoes. Chikungunya is a common species in nearly 40 countries across Africa and Asia. Environmental management regimes seek to minimize mosquito propagation, and therefore also disease transmission, by destroying, altering, removing, or recycling nonessential containers that provide larval habitats for mosquito species who may be vectors in the transmission of dengue fever (WHO, 2003). After this investigation, we introduced a control program against the mosquito to Piis-Paneu Island. The purposes of program are to increase the concern of residents about dengue fever and to reduce habitats of mosquito larvae.

\section{ACKNOWLeDgements}

We are very grateful to Mason Fritz, Director of Chuuk Visitors Bureau, who helped conduct research in Chuuk Lagoon. We wish to thank the following people for arranging my surveys in Chuuk Lagoon: Neterik (Sally Poll) on Weno Island, Tomisian Tan on Romanum Island, and Benito Nereo and Julian Kinoch on PiisPaneu Island. We could not have made our surveys as efficient without their warmhearted and persevering help. This work was supported by the Japan Society for the Promotion of Science (Project No. 22510271 and 24402006).

\section{REFERENCES}

Bohart, R. M. 1957. Insects of Micronesia Diptera: Culicidae. Bernice P. Bishop Musium. Insects of Micronesia, 1956 (12): 1-85.

Bohart, R. M. and Ingram, R. L. 1946. Mosquitoes of Okinawa and Islands in the Central Pacific. U. S. Navmed., 1055: 1-110.
Duffy, M. R., Chen, T., Hancock, W. T., Powers, A. M., Kool, J. L., Lanciotti, R. S., Pretrick, M., Marfel, M., Holzbauer, S., Dubray, C., Guillaumot, L., Griggs, A., Bel, M., Lambert, A. J., Laven, J., Kosoy, O., Panella, A., Biggerstaff, B., Fischer, M. and Hayes, E. B. 2009. Zika virus outbreak on Yap Island, Federated States of Micronesia. N. Engl. J. Med., 360: 2536-2543. doi:10.1056/NEJMoa0805715

Effler, P. V., Pang, L., Kitsutani, P., Vorndam, V., Nakata, M., Ayers, T., Elm, J., Tom, T., Reiter, P., Rigau-Perez, J. G., Hayes, J. M., Mills, K., Napier, M., Clark, G. G. and Gubler, D. J.; Hawaii Dengue Outbreak Investigation Team. 2005. Dengue fever, Hawaii, 20012002. Emerg. Infect. Dis., 11: 742-749. doi:10.3201/eid1105.1063

Galbraith, K., Bendure, G. and Friary, N. 2000. Micronesia 4th edition. 368 pp., Lonely Planet Publications, Hawthorn.

Hayes, E. B. 2009. Zika virus outside Africa. Emerg. Infect. Dis., 15: 1347-1350. doi:10.3201/eid1509.090442

Martin, B. 2005. Dengue fever type 1 outbreak in Yap. InformaACTION $n^{\circ} 20: 11-12$.

Ministry of Foreign Affairs of Japan 2011. Overseas Safety HP. Available from: http://www2.anzen.mofa.go.jp/info/pcspotinfo. asp?infocode $=2011 \mathrm{C} 370$

Ministry of Foreign Affairs of Japan 2012. Overseas Safety HP. Available from: http://www2.anzen.mofa.go.jp/info/pcspotinfo. asp?infocode $=2012 \mathrm{C} 360$

Noda, S., Gilmatam, J., Ogino, K., Toma, T. and Miyagi, I. 2005. Mosquitoes collected on Yap Islands and Ulithi Atoll, Yap State, Federated States of Micronesia (Diptera: Culicidae). Med. Entomil. Zool., 56: 349-353.

Noda, S., Yamamoto, S. and Toma, T. 2013a. Mosquitoes collected on Pohnpei Island, Mokil Atoll and Pingelap Atoll, Pohnpei State, the Federated States of Micronesia (Diptera: Culicidae). Med. Entomol. Zool., 64: 1-5.

Noda, S., Yamamoto, S., Toma, T. and Taulung, L. 2013b. Mosquitoes collected on Kosrae Island, Kosrae State, the Federated States of Micronesia. Trop. Med. Hyg., 41: 157-161.

Nukui, Y., Tajima, S., Kotani, A., Ito, M., Takahashi, T., Koike, K. and Kurane, I. 2006. Novel dengue virus type 1 from travelers to Yap State, Micronesia. Emerg. Infect. Dis., 12: 343-346. doi:10.3201/ eid1202.050733

Savage, H. M., Frits, C. L., Rutstein, D., Yolwa, A., Vorndam, V. and Gulbler, D. J. 1998. Epidemic of Dengue-4 virus in Yap State, Federated States of Micronesia, and implication of Aedeshensilli as an epidemic vector. Am. J. Trop. Med. Hyg., 59: 519-524.

Tanaka, K. 2003. Studies of the pupal mosquitoes of Japan (9). Genus Lutzia, with establishment of two new subgenera, Metalutzia and Insulalutzia (Diptera, Culicidae). Jpn. J. Syst. Entomol., 9: 159-169. WHO. 2003. Guidelines for Dengue Surveillance and Mosquito Control (Second edition). 105 pp., World Health Organization, Regional Office for the Western Pacific, Manila.

WHO. Number of cases of dengue fever and dengue hemorrhagic fever (DF/DFS) in the Western Pacific Region, 2000-2010. Available from: http://www.wpro.who.int/emerging_diseases/ WPRO_Dengue_Cases_2010.pdf. 